\title{
Dual-Function Reporter Protein for Analysis of Gene Expression in Living Cells
}

BioTechniques 25:848-856 (November 1998)

Richard N. Day, Margaret
Kawecki and Diana Berry

University of Virginia Health

Sciences Center, Charlottesville, VA, USA

\section{INTRODUCTION}

Recent advances in reporter gene technology, coupled with improvements in digital imaging systems, has led to the development of methods to visualize events as they occur within the living cell. For example, the luciferase (Luc) protein has proven to be especially useful as a quantitative reporter of transcription from living cells. The genetic incorporation of the luc reporter gene in plants (17), Drosophila $(2,21)$ and mice (10) has allowed reliable recording of bidirectional changes in transcriptional activity from the whole organism or tissue preparations over many days. These experimental systems illustrate the usefulness of Luc in monitoring dynamic changes in transcriptional activity over time from living cell populations. However, it has proven technically challenging to quantify the extremely low-level luminescent signal obtained from single living cells expressing Luc $(3,23)$. This particular application could be made more generally accessible if a biological marker were available to positively identify individual cells expressing high levels of the Luc reporter protein in advance of acquiring a luminescent signal.

The cloning of the jellyfish green fluorescent protein (GFP) (22) and its expression in a variety of cell types $(4,20)$ demonstrated this protein to be a versatile molecular reporter in living cells. GFP retains its characteristic fluorescence when fused to other protein sequences. When illuminated by the appropriate wavelength of light, the fusion proteins yield a bright green fluorescence that does not require any cofactors, substrates or additional gene products $(4,9,14)$. A relatively slow posttranslational cyclization and oxida- tion reaction is required to produce the chromophore of GFP (12). Once formed, GFP is a remarkably stable protein that is resistant to most proteases, limiting its use as a molecular reporter of bidirectional changes in gene expression (6). However, the protein has proven to be a bright, stable biological marker in living cells.

Because of their unique properties, both Luc and GFP have great utility as molecular reporters of cellular events, each being practical for addressing a specific set of biological questions. A genetic vector that encoded a chimeric protein with both fluorescent and bioluminescent properties could potentially exploit the strengths of each of these reporter proteins. We describe here a genetic vector encoding a protein fusion between GFP and Luc that retains both the fluorescent and luminescent characteristics of the individual proteins. This chimeric protein allows the use of fluorescent microscopy to rapidly identify cells expressing the transgene. Luc enzymatic activity can then be monitored continuously from the identified cells to assess dynamic changes in reporter gene activity.

\section{MATERIALS AND METHODS}

\section{Recombinant DNA Vector Construction}

The $l u c$ sequence encoding a cytoplasmic-targeted form of Luc (26) was subcloned into a plasmid vector containing a mutated $g f p$ cDNA with the serine to threonine substitution at chromophore position 65 (S65T) and optimized human codon usage (5). The linker between $l u c$ and $g f p$ cDNAs provided an in-reading-frame sequence 
encoding the 19-amino acid (aa) sequence PGILASQSTCRHASLRPIQ. This $g f p$-luc sequence was then inserted into a mammalian expression vector containing the cytomegalovirus promoter (pCMV), simian virus 40 (SV40) polyadenylation signal (An) and ampicillin (Amp) resistance gene (16) to generate the pCMV $g f p$-luc vector (Figure 1a).

\section{Cell Culture and Transfection}

Monolayer cultures of GH3 or HeLa cells were maintained in a 1:1 mixture of phenol red-free Ham's F12:Dulbecco's modified Eagle medium (Sigma Chemical, St. Louis, MO, USA) supplemented with $10 \%$ serum. For transient transfection, the pCMV gfp-luc fusion protein expression vector DNA was introduced into the cells by electroporation as previously described (8). Following electroporation, the cells were immediately diluted in medium and used to inoculate $60-\mathrm{mm}$ culture dishes for analysis of Luc activity or 35-mm culture dishes containing 25-mm glass coverslips for fluorescence microscopy. After overnight incubation at $33^{\circ} \mathrm{C}$ (19) in a humidified $5 \% \mathrm{CO}_{2}$ incubator, the cells were maintained at $37^{\circ} \mathrm{C}$.

\section{Immunoprecipitation and Western Blotting}

Transiently transfected cells were lysed at $4^{\circ} \mathrm{C}$ in detergent buffer as described previously (7). For immunoprecipitation, cell lysates $(0.5 \mathrm{~mL})$ were incubated overnight at $4^{\circ} \mathrm{C}$ with the anti-GFP antibody (Molecular Probes, Eugene, OR, USA) 1:1000 final dilution. Protein A Agarose (Boehringer Mannheim, Indianapolis, IN, USA) was added for an additional $4 \mathrm{~h}$ at $4^{\circ} \mathrm{C}$. Agarose pellets were washed three times in detergent buffer, and then bound proteins were removed by boiling in $2 \times$ Laemmli buffer (15). The proteins were fractionated by sodium dodecyl sulfate polyacrylamide gel electrophoresis (SDS-PAGE), transferred to nitrocellulose by electroblotting and detected by Ponceau S staining. Blocking buffers were $5 \%$ non-fat dried milk in Tris-buffered saline with Tween ${ }^{\circledR} 20$ (TBST) buffer (20 mM Tris-HCl, $\mathrm{pH}$ 7.6, $137 \mathrm{mM} \mathrm{NaCl}, 0.1 \%$ Tween 20). The primary antibodies were anti-GFP antibody, 1:10000 final dilution, and anti-Luc antibody (Sigma Chemical), 1:5000 final dilution. The secondary antibody was a horseradish peroxidaseconjugated anti-rabbit Ig (Pierce Chemical, Rockford, IL, USA), and antibody binding was detected using electrochemiluminescence (ECL $\left.{ }^{\mathrm{TM}}\right)$ reagents (NEN Life Science Products, Boston, MA, USA).

\section{Analysis of Luc Activity}

Luciferase enzymatic activity in extracts from transfected cells was determined as described previously (7). Light emission from the samples was measured using a Turner Model 20e Luminometer (Turner Designs, Sunnyvale, CA, USA) following the addition of $100 \mu \mathrm{L}$ of $0.4 \mathrm{mM}$ D-luciferin

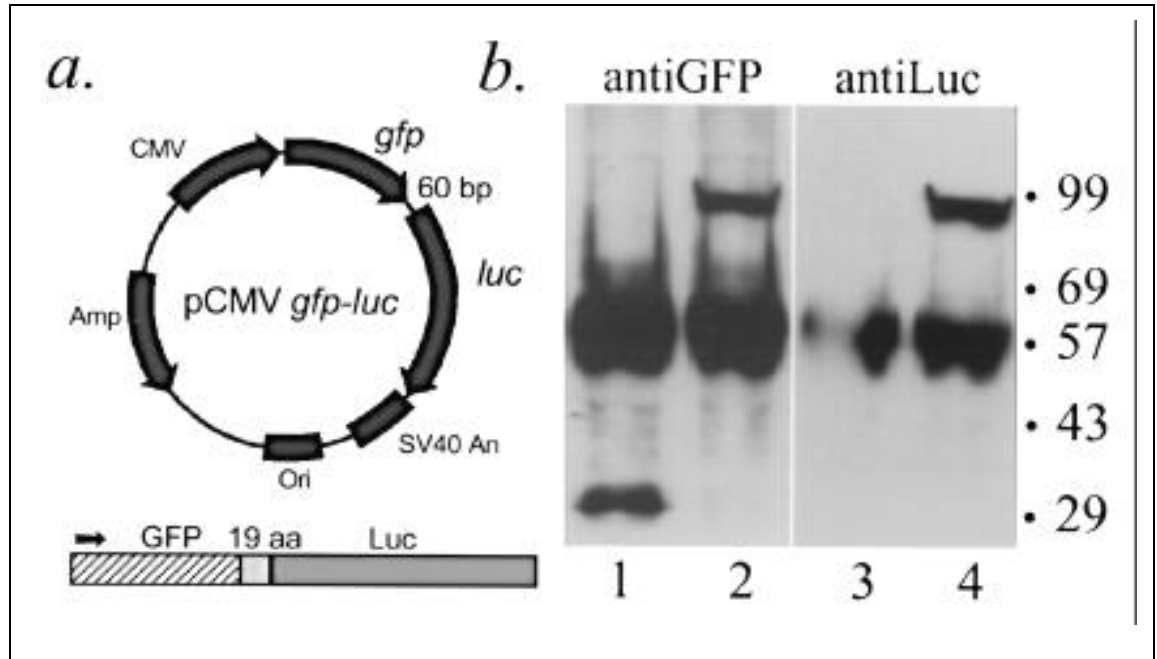

Figure 1. GFP-Luc protein expression. (a) A physical map of the pCMV $g f p$-luc expression vector. (b) Western blotting of protein extracts from $\mathrm{GH} 3$ cells transiently transfected with an expression vector encoding GFP alone or the vector encoding GFP-Luc. Immunoprecipitates were prepared using the GFPspecific antibody and analyzed by Western blotting using the GFP-specific antibody (lanes 1 and 2) or the antibody directed against Luc (lanes 3 and 4). Lanes: 1, GFP; 2, GFP-Luc; 3, GFP; and 4, GFP-Luc; numbers indicate migration of molecular size markers $(\mathrm{kDa})$.

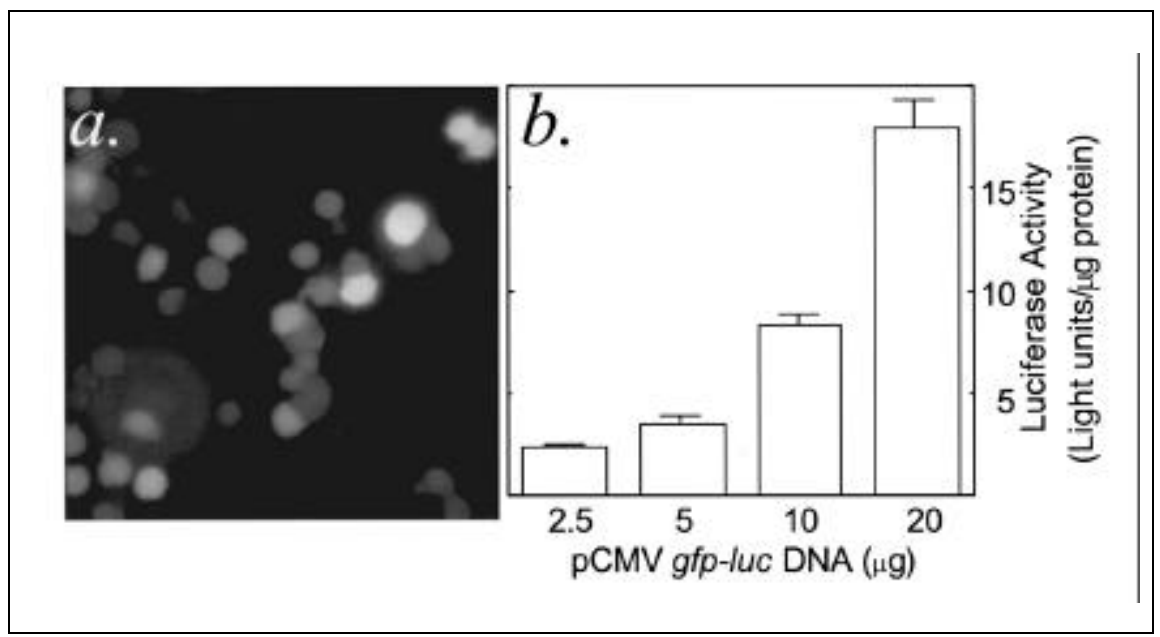

Figure 2. GFP-Luc protein activity. (a) Fluorescence microscopy of GFP-Luc expression in living cells. GH3 cells were transiently transfected with the pCMV $g f p$-luc vector and imaged after $24 \mathrm{~h}$ in culture using a 20× objective and inverted fluorescence microscope. GFP fluorescence emission from the living cells was detected at $535 \mathrm{~nm}$ using illumination at the excitation wavelength of $485 \mathrm{~nm}$. The image was acquired using a 35-mm camera. (b) Luc enzymatic activity from protein extracts prepared from the GH3 cells transfected with the indicated amount of the pCMV gfp-luc vector was then determined. Results are from triplicate transfections \pm standard error of the mean (SEM). 
(Promega, Madison, WI, USA). Total protein was determined using the Bio$\operatorname{Rad}^{\circledR}$ Protein Assay (Bio-Rad, Hercules, CA, USA).

\section{Analysis of Reporter Protein Stability}

A stable GH3 cell line expressing the GFP-Luc protein was generated by cotransfection with the pCMV $g f p$-luc plasmid and a second plasmid encoding the hygromycin-resistance gene. The cells were grown in medium containing $100 \mu \mathrm{g} / \mathrm{mL}$ hygromycin (Sigma Chemical), and colonies of cells surviving the selection were isolated with cloning rings and used to inoculate stock cultures. A population of cells expressing high levels of the fusion protein, assessed by Luc activity, was selected for further studies. These cells were harvested and used to inoculate $1228-\mathrm{mm}$, flat-bottomed borosilicate glass vials. The cultures were maintained in growth medium containing $1 \mathrm{mM}$ luciferin for $24 \mathrm{~h}$ at $37^{\circ} \mathrm{C}$ in a humidified $5 \% \mathrm{CO}_{2}$ incubator. To assess protein stability, 40 $\mu \mathrm{g} / \mathrm{mL}$ of the translation-inhibitor cycloheximide (Chx) (Sigma Chemical) were added to six of the vials, while the remaining vials received vehicle alone. Sequential determinations of cellular light emission was made for each vial at 0.5 -h intervals for $6 \mathrm{~h}$. The recovery of luminescence was assessed at $20 \mathrm{~h}$ following wash out and medium exchange.

\section{Cell Imaging}

Both fluorescence and luminescence images of cells were acquired using either a $20 \times$ or $40 \times$ objective lens and inverted microscope equipped for epifluorescence and transmitted illumination (Model IX-70, Universal Infinity System; Olympus America, Lake Success, NY, USA). For fluorescence imaging, the excitation light source was a 100-W mercury-xenon arc lamp (Hamamatsu Photonic Systems, Bridgewater, NJ, USA) coupled to an excitation filter $(485 / 20 \mathrm{~nm})$ wheel. The emission filter $(535 / 50 \mathrm{~nm})$ wheel was coupled to the output port of the microsocope and then to the camera. The luminescence images were acquired using a slow-scan, liquid-nitrogen-cooled charge-coupled device (CCD) camera with a backthinned, back-illuminated imaging chip
(Model CH260; Photometrics, Tucson, AZ, USA). The digital image output of the camera is $512 \times 512$ pixels with 16 bits resolution. For imaging of luminescence, the room was made completely dark, and the microscope stage was covered. A 1-min integration was obtained with the CCD camera to detect any light leaks, and the camera was then set for a 1-h integration.

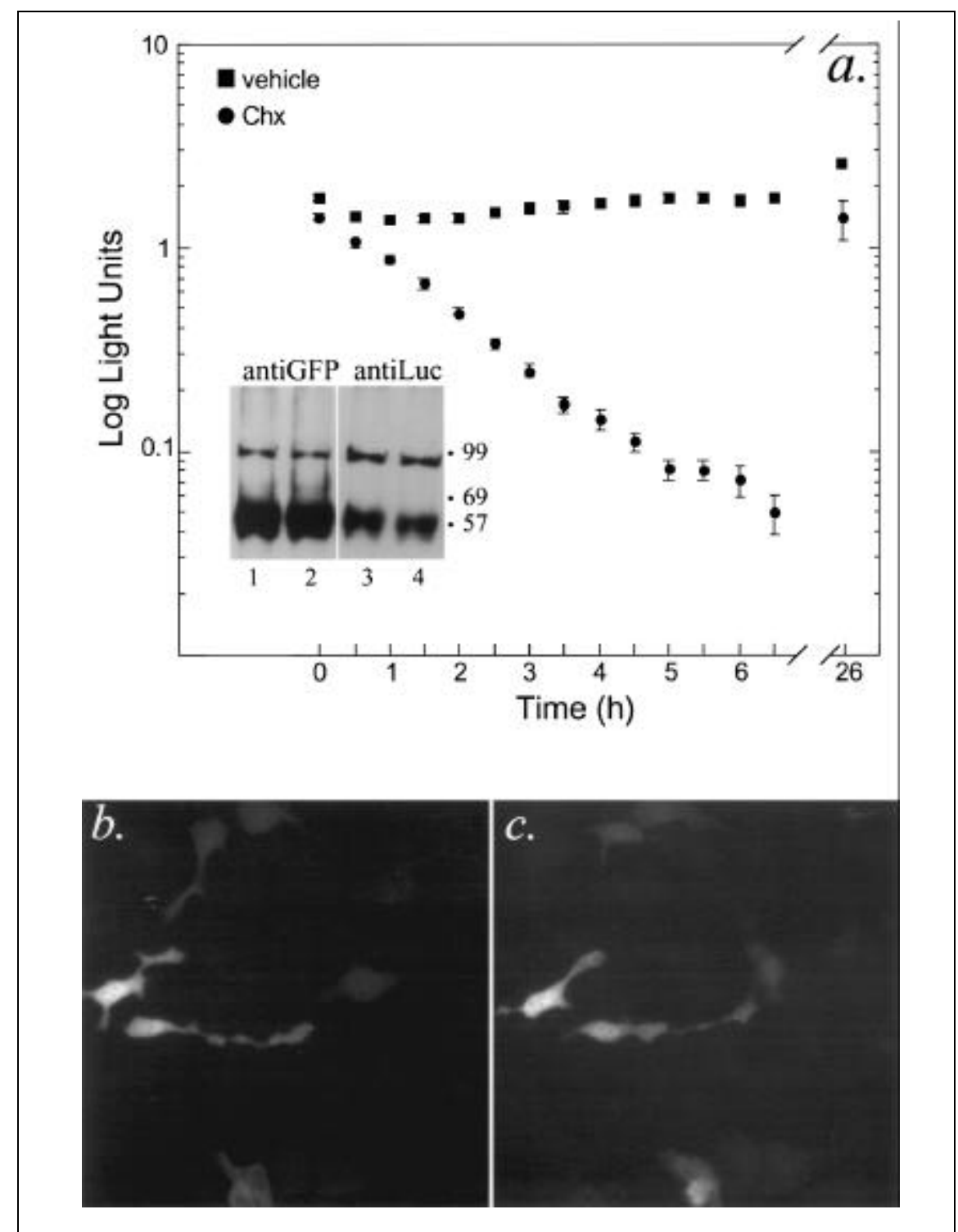

Figure 3. Determination of GFP-Luc protein stability. (a) Luminescence from a GH3 cell line stably expressing the GFP-Luc protein was monitored following treatment with Chx. Twelve independent cell cultures were maintained at $37^{\circ} \mathrm{C}$. At time 0,6 cultures received vehicle alone ( $\left.\mathbf{\square}\right)$, and the remaining 6 cultures received $40 \mu \mathrm{g} / \mathrm{mL} \mathrm{Chx}(\bullet)$. Cellular light emission was quantified over 15 -s integration periods at 0.5 -h intervals for $6 \mathrm{~h}$ as described in Materials and Methods. At the end of the 6-h treatment period, the cultures were rinsed, the medium was exchanged and recovery from protein translation inhibition was assessed after $20 \mathrm{~h}$ (note break in abscissa). Results are plotted as mean luminescence \pm SEM. Inset: Protein extracts were prepared from cells at time 0 and at $6 \mathrm{~h}$ of treatment with Chx . Following immunoprecipitation, samples were analyzed by Western blotting using the GFP-specific antibody (lanes 1 and 2) or the antibody directed against Luc (lanes 3 and 4). Lanes: 1 , time $0 \mathrm{~h} ; 2$, time $6 \mathrm{~h} ; 3$, time $0 \mathrm{~h} ; 4$, time 6 $\mathrm{h}$; numbers indicate migration of molecular size markers (kDa). (b) Fluorescence microscopy of GFPLuc expression in living cells following treatment with Chx. A fluorescence image of HeLa cells expressing GFP-Luc was obtained using a $20 \times$ objective lens. (c) The cells were then maintained in medium containing Chx for $6 \mathrm{~h}$, and a second fluorescence image of the same field was acquired under identical conditions as in Panel b. 


\section{RESULTS AND DISCUSSION}

\section{Analysis of Dual-Reporter Protein Functions}

Cells were transiently transfected with the pCMV $g f p$-luc vector (Figure 1a) or a vector encoding GFP alone. Protein extracts were prepared from the transfected cells after $24 \mathrm{~h}$ in culture. Immunoprecipitates were prepared using the GFP-specific antibody and analyzed by Western blotting as described in Materials and Methods. Probing the Western blot with the antibody specific for GFP detected both GFP, migrating at molecular mass of approximately 29 $\mathrm{kDa}$ and the recombinant GFP-Luc protein migrating at the predicted molecular mass of $89.5 \mathrm{kDa}$ (Figure 1b). The protein migrating at approximately $55 \mathrm{kDa}$ is IgG. The blot was then stripped and reprobed with the antibody directed against Luc. The chimeric GFP-Luc protein was again detected (Figure 1b), confirming that a single recombinant protein containing both epitopes was synthesized in the transfected cells.

The enzymatic activity of Luc and the fluorescence from GFP were then assessed using GH3 cells transfected with the pCMV $g f p$-luc vector. Observation of the transfected cells by fluorescence microscopy revealed many brightly fluorescent cells (Figure 2a), indicating that GFP was functionally expressed. Protein extracts were prepared from the transfected cells, and Luc activity, corrected for total protein content, was determined. Figure $2 b$ shows Luc activity increased in proportion to the amount of expression vector used for transfection. Fluorescence from GFP requires that the entire protein be intact and that it fold into a $\beta$ barrel structure surrounding the central chromophore $(6,18)$. Moreover, the $\mathrm{C}$ terminal 12 aa of Luc were shown to be necessary for enzymatic activity (25). The results presented here showed that within the context of the GFP-Luc fusion protein, GFP was able to fold appropriately for chromophore formation, and that the complete Luc protein was synthesized and fully functional.

\section{Recombinant Reporter Stability}

The feature that distinguishes Luc from other reporter proteins is its relatively short half-life $(21,27,28)$. Thompson et al. (27) reported that Luc turned over in human hepatoblastoma cell line in approximately $3 \mathrm{~h}$. Although Luc lacks signals commonly found in unstable proteins, it was demonstrated to be susceptible to proteolysis. It is not possible to predict how the fusion of two proteins with disparate stabilities would influence the individual protein halflives. For example, fusion of protein

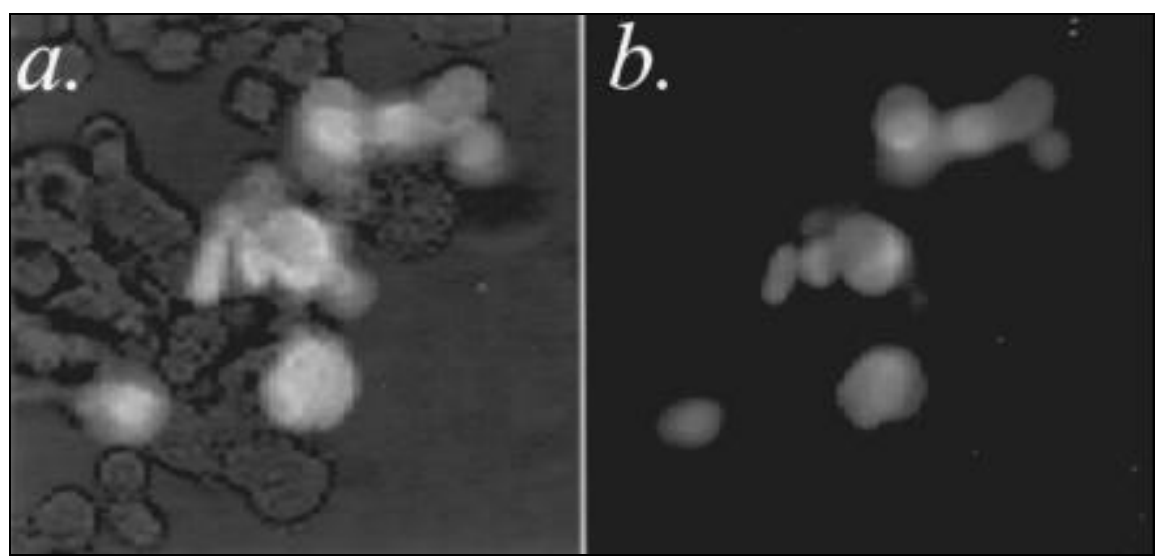

Figure 4. Imaging fluorescence and luminescence from single living cells. (a) Identification of single cells expressing GFP-Luc. GH3 cells transiently transfected with the pCMV gfp-luc vector were grown on glass coverslips as described above. Bright-field illumination was used to acquire a focused image of the cells. The coverslip was then scanned for cells expressing GFP using illumination at $485 \mathrm{~nm}$ and monitoring emission at $535 \mathrm{~nm}$. The fluorescence image was acquired using a CCD camera as described in Materials and Methods, and the image was projected on the bright-field image of the cells to positively identify those cells expressing the GFP-Luc protein. (b) Imaging luminescence from single identified cells. Luciferin was added to the culture media to a final concentration of $1 \mathrm{mM}$. A 1-h, on-chip integrated image of light output from the cells was then obtained. 
motif from cyclin that contributes to rapid protein degradation, to human thymidine kinase, resulted in a destabilized protein. However, this instability was found to be dependent upon protein context (24). In yeast, regulated degradation of the GFP fused to the hydroxy methylglutaryl-CoA reductase protein was reported (11). Since rapid turnover is the distinguishing characteristic of Luc, it was important to determine how fusion to GFP influenced protein half-life.

Treatment of a GH3 cell line stably expressing the GFP-Luc fusion protein with the translation-inhibitor Chx was used to estimate the turnover of Luc enzymatic activity and GFP fluorescence. Figure 3 shows Luc enzymatic activity decayed with a half-life of approximately $2 \mathrm{~h}$ for cells maintained at $37^{\circ} \mathrm{C}$. This decrease in Luc activity was not a result of cell death, because enzymatic activity recovered following wash out of the drug (Figure 3). Western blotting was used to determine if proteolytic degradation of the recombinant protein contributed to the rapid inactivation of Luc. Probing with the antibodies specific for either GFP (Figure 3, inset lanes 1 and 2) or Luc (Figure 3, inset lanes 3 and 4) revealed no significant change in molecular mass of the recombinant protein from time 0-6-h treatment with Chx. It is possible that inactivation of Luc resulted from proteolytic cleavage of the terminal 12 aa (25), which would not have been detected here. Significantly, fluorescence from the GFP-Luc protein was not affected by a 6-h treatment with Chx (compare Figure $3 \mathrm{~b}$ with $3 \mathrm{c}$ ). These results demonstrated that the chimeric reporter protein retained the characteristic rapid turnover of the Luc reporter protein and suggested that, even after Luc protein inactivation, the GFP chromophore remained intact.

\section{Imaging Fluorescence and Lumines- cence from Single Living Cells}

The fluorescence from the GFP-Luc protein provides a way to rapidly identify individual transfected cells within a population, while luminescence from these same cells could potentially report changes in gene activity. To test this application, individual cells expressing the fusion protein were identified using fluorescence microscopy (Figure 4a). The relative intensity of fluorescence from any individual cell is a function of number of proteins expressed (19). For the chimeric GFP-Luc protein, fluorescence intensity should also be directly proportional to Luc protein levels. After identifying fluorescent cells expressing the recombinant protein, luciferin was added to the culture medium, and a 1-h integrated image of luminescence was acquired using a sensitive cryogenic CCD camera (Figure 4b). A quantifiable luminescent signal was detected from each of the identified cells. The intensity of the luminescent signal was proportional to the fluorescence signal from the same cell.

The recombinant dual-function reporter protein described here takes advantage of the characteristics of both Luc and GFP for monitoring of gene expression from living cells. Since GFP can be easily detected in single cells by fluorescent microscopy, it is possible to rapidly identify individual cells ex- pressing GFP-Luc within the greater population, even when the percentage of expressing cells is very low. Fluorescence from the transfected cells can be used in fluorescence-activated cell sorting (FACS) to isolate an enriched population of cells expressing the chimeric reporter protein. Importantly, the chimeric protein described here has retained the characteristic rapid turnover of Luc enzymatic activity. Luc activity from populations of cells enriched by FACS could be monitored continuously using photon-counting devices, and single-cell determination of Luc activity becomes more tenable, because individual cells expressing high levels of the transgene are easily identified. Also, this chimeric protein might be of use as a reporter in transgenic animals. Tissue distribution of the transgene could potentially be mapped using the GFP, while the dynamics of transgene expression in tissue slice or dispersed cell culture could be monitored using Luc. Another important application of in vivo expression of GFP-Luc could be in "enhancer-trap" studies to locate strong enhancer sequences through positional effects (1). Through the use of a weak promoter controlling GFP-Luc expression, only transgenic lines in which promoter integration is proximal to a strong enhancer would be detected. The expression pattern of GFP-Luc in transgenic lines would be an indirect reflection of both the tissue specificity and strength of nearby enhancers (13). The advantage of the chimeric protein is that temporal patterns of enhancer activity could also be monitored using Luc activity. This approach could potentially be used to identify novel genes and regulatory flanking sequences that have interesting tissue and temporal patterns of expression during development.

\section{CONCLUSIONS}

(i) The GFP-Luc fusion protein is useful in the rapid detection of transfected cells in living cell populations irrespective of transfection efficiency. This positive identification of transfected cells makes the approach of single cell imaging of Luc activity more practical. (ii) Because of the relatively rapid turnover of Luc enzymatic activity for 
the GFP-Luc recombinant protein in mammalian cells, this dual-function reporter protein remains useful for monitoring dynamic bidirectional changes in gene activity in transfected cells and transgenic animal tissues.

\section{ACKNOWLEDGMENTS}

We wish to thank Drs. Bruce Sherf and Keith Wood of the Promega Corporation for providing the mutant luc plasmid and Dr. Jen Sheen (Massachusetts General Hospital, Boston, MA, USA) for providing the mutant $g f p$ with optimized codon usage. Imaging of luciferase was performed with the expert assistance of Ammasi Periasamy at the University of Virginia Advanced Cellular Imaging Facility. This work was supported by awards from the National Science Foundation (NSF) DIR-8920162 Center for Biological Timing Technology Development sub-project (R.N.D.) and NSF SGER IBN9528526 (R.N.D.).

\section{REFERENCES}

1.Alam, J. and J.L. Cook. 1990. Reporter genes: application to the study of mammalian gene transcription. Anal. Biochem. 188:245254.

2.Brandes, C., J.D. Plautz, R. Stanewsky, C.F. Jamison, M. Straume, K.V. Wood, S.A. Kay and J.C. Hall. 1996. Novel features of drosophila period transcription revealed by real-time luciferase reporting. Neuron 16:687692.

3.Castaño, J.P., R.D. Kineman and L.S. Frawley. 1996. Dynamic monitoring and quantification of gene expression in single, living cells: a molecular basis for secretory cell heterogeneity. Mol. Endocrinol. 10:599-605.

4.Chalfie, M., Y. Tu, G. Euskirchen, W.W. Ward and D.C. Prasher. 1994. Green fluorescent protein as a marker for gene expression. Science 263:802-805.

5.Chiu, W., Y. Niwa, W. Zeng, T. Hirano, H. Kobayashi and J. Sheen. 1996. Engineered GFP as a vital reporter in plants. Curr. Biol. 6:325-330.

6.Cubitt, A.B., R. Heim, S.R. Adams, A.E. Boyd, L.A. Gross and R.Y. Tsien. 1995. Understanding, improving and using green fluorescent proteins. Trends Biochem. Sci. 20:448-455.

7.Day, R.N. and K.H. Day. 1994 Specific repression of rat prolactin gene expression in transplanted tumor cells. Mol. Endocrinol. 8:12-20.

8.Day, R.N. and R.A. Maurer. 1990. Pituitary calcium channel modulation and regulation of prolactin gene expression. Mol. Endocrinol. 4:736-742.

9.Gerdes, H.H. and C. Kaether. 1996. Green fluorescent protein: applications in cell biology. FEBS Lett. 389:44-47.

10.Geusz, M.E., C. Fletcher, S.A. Kay, G.D. Block, M. Straume, N.G. Copeland, N.A. Jenkins and R.N. Day. 1997. Long-term monitoring of rhythmic c-fos gene expression from mouse brain explant cultures. Curr. Biol. 8:758-766.

11.Hampton, R.Y., A. Koning, R. Wright and J. Rine. 1996. In vivo examination of membrane protein localization and degradation with green fluorescent protein. Proc. Natl. Acad. Sci. USA 93:828-833.

12.Heim, R. and R.Y. Tsien. 1996. Engineering green fluorescent protein for improved brightness, longer wavelengths and fluorescence resonance energy transfer. Curr. Biol. 6:178182.

13.Kain, S. and S. Ganguly. 1995. Overview of genetic reporter systems, p. 9.6.1-9.6.12. In F.M. Ausubel, R. Brent, R.E. Kingston, D.D. Moore, J.G. Seidman, J.A. Smith and K. Struhl (Eds.), Current Protocols in Molecular Biology. John Wiley \& Sons, New York.

14.Kain, S.R., M. Adams, A. Kondepudi, T.-T. Yang, W.W. Ward and P. Kitts. 1995. Green fluorescent protein as a reporter of gene expression and protein localization. BioTechniques 19:650-655.

15.Laemmli, U.K. 1970. Cleavage of structural proteins during the assembly of the head of bacteriophage T4. Nature 227:680-685.

16.MacGregor, G.R. and C.T. Caskey. 1989.
Construction of plasmids that express $E$. coli beta-galactosidase in mammalian cells. Nucleic Acids Res. 17:2365.

17.Millar, A.J., M. Straume, J. Chory, N.H. Chua and S.A. Kay. 1995. The regulation of circadian period by phototransduction pathways in Arabidopsis. Science 267:1163-1166.

18.Ormö, M., A. Cubitt, K. Kallio, L.A. Gross, R.Y. Tsien and S.J. Remington. 1996. Crystal structure of the Aequorea victoria green fluorescent protein. Science 273:1392-1395.

19.Patterson, G.H., S.M. Knobel, W.D. Sharif, S.R. Kain and D.W. Piston. 1997. Use of the green fluorescent protein and its mutants in quantitative fluorescence microscopy. Biophys. J. 73:2782-2790.

20.Plautz, J.D., R.N. Day, C.M. Dailey, S.B. Welsh, J.C. Hall, S. Halpain and S.A. Kay. 1996. Green fluorescent protein and its derivatives as versatile markers for gene expression in living Drosophila melanogaster, plant and mammalian cells. Gene 173:83-87.

21.Plautz, J.D., M. Straume, R. Stanewsky, C.F. Jamison, C. Brandes, H.B. Dowse, J.C. Hall and S.A. Kay. 1997. Quantitative analysis of Drosophila period gene transcription in living animals. J. Biol. Rhythms 12:204-217.

22.Prasher, D.C., V.K. Eckenrode, W.W. Ward, F.G. Prendergast and M.J. Cormier. 1992. Primary structure of the Aequorea victoria green-fluorescent protein. Gene 111:229-233.

23.Rutter, G.A., M.R.H. White and J.M. Tavaré. 1995. Involvement of MAP kinase in insulin signalling revealed by noninvasive imaging of luciferase gene expression in single living cells. Curr. Biol. 5:890-899.

24.Salama, S.R., K.B. Hendricks and J. Thorner. 1994. G1 cyclin degradation: the PEST motif of yeast $\operatorname{Cln} 2$ is necessary, but not sufficient, for rapid protein turnover. Mol. Cell Biol. 14:7953-7966.

25.Sala-Newby, G.R. and A.K. Campbell. 1994. Stepwise removal of the C-terminal 12 amino acids of firefly luciferase results in graded loss of activity. Biochim. Biophys. Acta 1206:155-160.

26.Sherf, B.A. and K.V. Wood. 1995. Firefly luciferase engineered for improved genetic reporting. Promega Notes 49:14-21.

27.Thompson, J.F., L.S. Hayes and D.B. Lloyd. 1993. Modulation of firefly luciferase stability and impact on studies of gene regulation. Gene 103:171-177.

28.Wood, K.V. 1995. Marker proteins for gene expression. Curr. Opin. Biotechnol. 6:50-58.

Received 13 May 1997; accepted 18 May 1998.

Address correspondence to:

Dr. Richard N. Day

Departments of Medicine and Cell Biology

National Science Foundation Center for

Biological Timing

University of Virginia Health Sciences Center

Charlottesville, VA 22908, USA

Internet: rnd2v@virginia.edu 